\title{
Body Language Without a Body: Nonverbal Communication in Technology Mediated Settings
}

\author{
Alessandro Vinciarelli \\ University of Glasgow \\ School of Computing Science \\ Glasgow, United Kingdom \\ Alessandro.Vinciarelli@glasgow.ac.uk
}

\begin{abstract}
Humans are wired for face-to-face interaction because this was the only possible and available setting during the long evolutionary process that has led to Homo Sapiens. At the moment an increasingly significant fraction of our interactions take place in technology mediated settings, it is important to investigate how such a wiring - mainly corresponding to neural processes - reacts and adapts to them. This talk focuses in particular on how nonverbal communication - one of the main channels through which people convey socially and psychologically relevant information - plays a role in settings where natural nonverbal cues (facial expressions, vocalizations, gestures, etc.) are no longer available. Such an issue is important not only from a technological point of view (it can help to design interaction and communication technologies that better address human needs), but also from a societal one (it can help to understand major phenomena such as cyberbullyism and virality).
\end{abstract}

\section{CCS CONCEPTS}

\section{-Computing methodologies $\rightarrow$ Biometrics;}

\section{KEYWORDS}

Social Signal Processing; Nonverbal Communication

\section{ACM Reference format:}

Alessandro Vinciarelli. 2017. Body Language Without a Body: Nonverbal Communication in Technology Mediated Settings. In Proceedings of AVEC'17, Mountain View, CA, USA, October 23, 2017, 2 pages.

DOI: https://doi.org/10.1145/3133944.3133954

\section{INTRODUCTION}

Nonverbal communication (facial expressions, vocalisations, gestures, etc.) plays a major role in human-human and human-machine interactions, especially when it comes to conveying information about social and psychological aspects [3]. Typically, psychologists group nonverbal cues into five major classes called the codes [4]:

- Physical Appearance: attractiveness, clothes, ornaments, body shape, etc.;

- Face and Head: facial expressions, head nods, head shakes, gaze, etc.;

Permission to make digital or hard copies of part or all of this work for personal or classroom use is granted without fee provided that copies are not made or distributed for profit or commercial advantage and that copies bear this notice and the full citation on the first page. Copyrights for third-party components of this work must be honored. For all other uses, contact the owner/author(s).

AVEC'17, October 23, 2017, Mountain View, CA, USA

(C) 2017 Copyright held by the owner/author(s). 978-1-4503-5502-5/17/10 ..\$15.00 DOI: https://doi.org/10.1145/3133944.3133954
- Gestures and Posture: orientation of the body with respect to others, self-touching, arm folding, spontaneous hand movements, etc.;

- Vocal: prosody, intonation, vocalizations (laughter, crying, filers), pauses, voice quality, etc.;

- Space and Environment: mutual distances, spatial formations, patterns of movement in public spaces, etc.

The taxonomy above includes only cues that can be perceived through the senses, meaning that they can be used only when people are physically co-located. The reason is that nonverbal communication is a natural phenomenon and it is the result of a long evolutionary process during which face-to-face interaction was the only available (and necessary) communication option [2]. Nowadays, technology makes it possible to interact at distance and it gives us the possibility to engage in social exchanges at virtually every moment and in virtually every place. However, such a freedom comes with a cost, namely the impossibility to use, partially or totally, the nonverbal cues listed above.

The natural question that arises from such a state-of-affairs is what happens in such a new situation, i.e., how the human brain - wired for face-to-face communication - processes the signals exchanged in technology mediated settings. Early works addressing explicitly such a question show that the typing patterns that people manifest in online textual chats are sufficiently specific of an individual to allow person recognition [1], that people speaking on the phone invest up to one quarter of their conversation time in nonverbal communication [6] and that the images that people tag as favourite on Flickr convey personality impressions [5, 9].

The works above - and the others that the literature presents provide initial indications, but several questions remain to be addressed. In particular, the overall main question that needs to find an answer is whether Social Signal Processing (SSP) $[7,8]$ - the computing domain aimed at modelling, analysis and synthesis of nonverbal communication in human-human and human-machine interactions - can be transferred to domains where natural nonverbal cues cannot be used.

\section{BIOGRAPHY}

Alessandro Vinciarelli (http://www.dcs.gla.ac.uk/vincia) is with the University of Glasgow where he is Full professor at the School of Computing Science and Associate Academic at the Institute of Neuroscience and Psychology. His main research interest is Social Signal Processing, the domain aimed at modelling analysis and synthesis of nonverbal behaviour in social interactions. In particular, Alessandro has investigated approaches for role recognition in multiparty conversations, automatic personality perception 


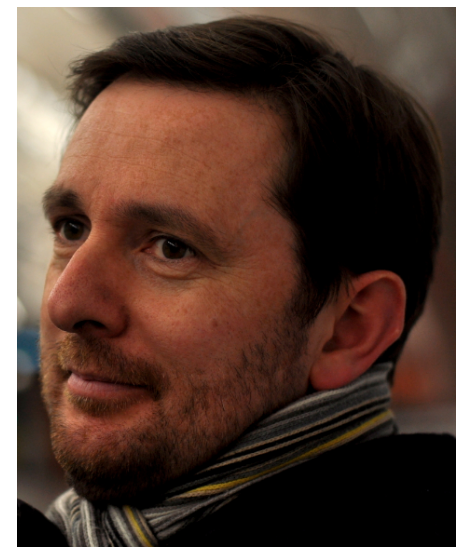

Figure 1: Alessandro Vinciarelli

from speech, and conflict analysis and measurement in competitive discussions.

Overall, Alessandro has published more than 120 works, including one authored book, seven edited volumes, and 36 journal papers. Alessandro has been general chair of the ACM international Conference on Multimodal Interactions in 2017, Program and General Chair of the IEEE International Conference on Social Computing (in 2011 and 2012, respectively), and has initiated and co-chaired several workshop series (Social Signal Processing Workshop, the International Workshop on Socially Intelligent Surveillance and Monitoring, the International Workshop on Human Behaviour Understanding, the Workshop on Political Speech and the Workshop on Foundations of Social Signals).
Furthermore, Alessandro is or has been Principal Investigator of over ten national and international projects, including a European Network of Excellence ${ }^{1}$, a H2020 project ${ }^{2}$, several projects funded by the Engineering and Physical Sciences research Council ${ }^{3}$, an Indo-Swiss Joint Research Project ${ }^{4}$ and an individual project in the framework of the Swiss National Centre of Competence in Research IM2 ${ }^{5}$. Last, but not least, Alessandro is co-founder of Klewel ${ }^{6}$, a knowledge management company recognized with several awards.

\section{REFERENCES}

[1] M. Cristani, G. Roffo, C. Segalin, L. Bazzani, A. Vinciarelli, and V. Murino. 2012 Conversationally-inspired stylometric features for authorship attribution in instant messaging. In Proceedings of the ACM International Conference on Multimedia. 1121-1124.

[2] R. Dunbar, L. Barrett, and J. Lycett. 2005. Evolutionary psychology: a beginner's guide. Oneworld Publications.

[3] M.L. Knapp and J.A. Hall. 1972. Nonverbal Communication in Human Interaction. Harcourt Brace College Publishers.

[4] V.P. Richmond and J.C. McCroskey. 1995. Nonverbal Behaviors in interpersonal relations. Allyn and Bacon.

[5] C. Segalin, A. Perina, M. Cristani, and A. Vinciarelli. 2017. The pictures we like are our image: continuous mapping of favorite pictures into self-assessed and attributed personality traits. IEEE Transactions on Affective Computing 8, 2 (2017), 268-285.

[6] A. Vinciarelli, P. Chatziioannou, and A. Esposito. 2015. When the words are not everything: the use of laughter, fillers, back-channel, silence, and overlapping speech in phone calls. Frontiers in ICT 2 (2015), 4.

[7] A. Vinciarelli, M. Pantic, and H. Bourlard. 2009. Social signal processing: Survey of an emerging domain. Image and Vision Computing 27, 12 (2009), 1743-1759.

[8] A. Vinciarelli, M. Pantic, D. Heylen, C. Pelachaud, I. Poggi, F. D’Errico, and M. Schroeder. 2012. Bridging the gap between social animal and unsocial machine: A survey of social signal processing. IEEE Transactions on Affective Computing 3 , 1 (2012), 69-87.

[9] X. Xiong, M. Filippone, and A. Vinciarelli. 2016. Looking Good With Flickr Faves: Gaussian Processes for Finding Difference Makers in Personality Impressions. In Proceedings of the ACM International Conference on Multimedia. 412-415.

\footnotetext{
$\overline{1_{\text {http: }} / / \text { www.sspnet.eu }}$

${ }^{2}$ http://mummer-project.eu

${ }^{3}$ e.g., http: //www. attachment-monitor.org.uk

${ }^{4}$ http://www.idiap.ch/project/ccpp/

${ }^{5}$ http://www. im2.ch

${ }^{6}$ http://www. klewel.com
} 